Paul Christie

How for the hands

\title{
How for the hands: An exploratory narrative for the actor
}

\section{discovering Active Analysis}

Paul Christie

Staffordshire University

Paul Christie trained on the BA acting degree at RSAMD before going on to work as a professional actor for ten years performing in theatre, training as a theatre director at RADA. He has combined directing with the teaching of acting for several years with a commitment to exploring and deepening the collaboration between actor, director and playwright in the rehearsal room. Most recently, he has published in the bilingual Stanislavski Studies journal published by Routledge on 'The method of analysis through action'. He is currently co-course leader of the Drama Department at Staffordshire University where he specializes in actor and director training.

Contact: Staffordshire University, College Road, Stoke-on-Trent, ST4 2DE, UK. . E-mail: p.christie@staff.ac.uk
Abstract
A commitment to exploring both form and content are the jumping off points for this article which examines the howness of the improvisatory rehearsal technique known as Active Analysis alongside the howness of writing about something as highly subjective as acting and actor training. Taking the format of the novel as its driving force with particular regard to the unique ability of the novel to communicate consciousness in a 
way which more traditionally academic formats cannot, it follows the story of Victor and his struggle to commit to a new way of experiencing his work, a new kind of howness. Along the way he discovers a great deal about the nature of process and how the kind of attention he pays to the world and his work alters the experience of what actually happens.

Keywords

active analysis

actor

consciousness

Stanislavski

\section{Introduction}

To write about acting whether it be with regards to actor training or rehearsal methods is ultimately to be writing about human experience; how human beings experience themselves and others. So it is in turn to be writing about consciousness, how a human being we call an actor attempts to use their consciousness in a particular way for a particular purpose.

Conscious experience being entirely subjective presents a challenge to those of us who wish to write about it and convey something useful to the reader. At times it feels like a little objectivity would be the perfect antidote, some clarity amidst the density of the chaos. Conscious experience remains entirely subjective however, and so the form of how we write about it becomes as important as the content. Perhaps the theatrical giant Stanislavski considered this in his choice to write An Actor's Work in the form of a 
somewhat fictional narrative of a young acting student. The form, the 'how' we might say is essential.

'The richest record we have of human consciousness', suggests the novelist and literary critic David Lodge (2002), is in the form of the novel, which offers 'a kind of knowledge about this phenomenon that is complementary, not opposed, to scientific knowledge'. For Lodge, the novel is able to capture the 'density of experienced events' as consciously experienced. It's surprising therefore that so little writing about the acting process utilizes the narrative form.

This article explores the potential for a novel like narrative to communicate the subjective nature of actor training and an actor's experience. For this reason, the article is as unobtrusively referenced as possible in order to not disrupt the reader's attention from the story. I am relying on the endnotes to give full credit where it is due and as such have given endnote numbers within the text wherever there is reason for acknowledgement. ${ }^{\mathrm{i}}$

\section{Hands $^{\text {ii }}$}

Should it be 'I'? Or 'we'? Or should it be 'they' being as that is how he thinks of us. These hands. ${ }^{1}$ Attached through those arms. His arms. Unmistakably his. Forty three years of attachment to these sentient tools of skin, blood and bone. For this is how long we have held his books, lifted his food to his mouth, scratched his itches, tended to his wounds inner and outer. Fed his many appetites. We held the girls he loved and those he didn't love with equal dexterity, we carried the feelings of those touches from skin to 
mind imperceptibly, we still do and always shall so long as form of body and form of mind continue.

Today is somehow different though. Somehow unusual. The past twenty five of those forty seven years of life have been habitually predictable in their work. For there is work and there is life and though work be part of life there is a difference as our man's work is a form of life itself. He does not work exclusively with wood or metal or the soil of the land but rather with all of these and none, for his work is to bring life from words on a page. Hence our work is to hold and lift and turn the page in time for the last syllable of one page to lead in to the first syllable of the next. We hold the pulped wood on which live the precisely shaped lines of ink which form his words and he in turn makes life from this. Wood dies but the word lives. Two hands alike in almost all measures yet not quite alike in dignity; since those early days when one of us, the one he names the left was consigned to stillness; holding the page flat to the table whilst the other, the right, practiced his first dances with words - cat, dog, sat, pin, victor, victor, Victor. The name, those early pencil play days always had the name, fascinated to play with the very symbols which created himself on the page. Was that the beginning perhaps? Of 'the self' itself? The beginning of the actor, the boy who played with words, loved words, the name on the page leading to the name up in lights. Yes, since those early days we have never felt alike in dignity. The left has always been the stiller of the two, the designated driver, soberly holding the script leaving the right free to continue the great pencil dance of markings and page turnings intermingled with occasional gestures; the right has always had a little more manoeuvre, more power, more respect. So two hands almost alike in dignity. 
Today's rehearsal was different however, twenty five years of script holding and pencil dancing has come to an end here, today. For today we were both free to do as we please; the old duties discarded in favour of new explorations. Today we touched the face of a young woman, but it wasn't the usual touch, the work touch, it was much more alike to the life touch, the touch he uses everywhere else. Suddenly this kind of touch has a place in the work and we have been brought in from the cold. We felt the touch all the way through his body and mind and felt it shake him like the time he touched the frog and it jumped that day in the park. The laughter shake. Perhaps it wasn't real work today. Perhaps it was something else. Back to normal tomorrow probably. Let's not get our hopes up. If hands are permitted hopes.

Anyway, must go, we're needed, he's reaching for something. The pen. The paper. Time to dance.

\section{Mind $^{\text {iii }}$}

First day of rehearsals for Vanya today, the assistant director - a pretty Japanese girl called Mariko - is doing a blog. Who isn't these days? She's rather unusually on attachment with us from the philosophy department of Cambridge University, studying phenomenology apparently. I don’t even know if I’ve spelt that right. She's asked us all if we might keep a diary and share anything we might consider appropriate as the weeks pass by. I immediately thought 'you can count me out', but then as the day progressed the idea grew on me a bit. Doubt any of my thoughts will be sharable with the general public anyway, but you never know. If this whole improvisatory rehearsal process is a car crash, it might make for entertaining reading, maybe it could become one of those infamous backstage accounts that does the rounds amongst those in the know. Well, here goes... 
It's Monday 13 January 2015, Christmas firmly in the background and I’m playing the title role in Anton Chekhov's Uncle Vanya - always wanted to play the part so not an opportunity to let slip by in spite of my concerns about the rehearsal process. When I read for the part the director explained the rehearsal process to me and I readily agreed that it sounded fascinating - of course I did I wanted the job! Deep down I was a little anxious about the idea however. We're using something called Active Analysis where you never get to take the script on to the rehearsal room floor with you but instead improvise your way to the actual script. There are five steps. The first three kicking off the process for each scene:

Read the scene

Discuss the scene

Improvise the scene

Then following the first improvisation of each scene the final two steps:

Discuss the improvisation relative to what's in the script Improvise the scene again

And this just keeps repeating until the scene is performed as written by the playwright. The idea is that we work our way from silent improvisations through to improvising using a few of our own words and then even more of our own words (perhaps alongside some of the playwright's words) until we end up speaking just the playwright's words as written. The director views it as pretty much a reversal of the standard rehearsal model in Britain where we traditionally start with words in order to try and experience further down the line. This way we begin with experience and try to find the words from that experience which makes good sense I suppose seeing as that's how 
life happens in the first place but I can’t help feeling it’s going to be hard work getting there. Life ain’t easy after all. Well mine isn't that's for sure.

The improvisations we did today were all silent; it was actually quite interesting being robbed of words for a while, for starters the pressure of proving that I'll be a brilliant Vanya wasn't there like it usually would be - it's alright with people you've worked with before but with strangers there's always that nagging need to prove you can 'do' it.

I think it's fair to say that I made some connections with other cast members that I don't usually make so soon - if ever, I suppose, being completely honest. The moment where I touched Hattie (the girl playing Sonia) on the face which made her laugh and then I laughed too for example. Sounds a bit trite now but I can't remember the last time I actually laughed for real with another actor. When acting that is, I laugh all the time with actors offstage obviously, but it's not the kind of thing that happens much in performance - a real out of my control laugh. From the gut.

In the discussion after it had obviously been a memorable moment for Sonia too which gave me a bit of confidence in the whole thing. Still, it kind of feels like I haven't done anything today, as if I haven't worked at all. I fear the whole day was frivolous, a guilty pleasure of sorts. Our improvisations bore little resemblance to the actual play. I wonder what Chekhov would say had he been watching; 'Get on with my play you lazy shits'. I expect. Perhaps a little less crude. So, yes, an okay day, interesting, but I hope we get on to speaking the lines soon. We've only got five weeks and this isn't Russia: they might have the time and inclination to splurge their inner spirit out over there, but here 
we keep our spirits buttoned up and deliver the goods in four weeks flat thanks very much.

We'll see what tomorrow brings.

\section{Feet}

Should it be 'I'? Or 'we'? Or should it be 'they' being as that is how he thinks of us.

These feet. Attached through those legs. His legs. Unmistakably his. Forty three years of attachment to these sentient tools of skin, blood and bone. For this is how long we have balanced his movements, ran his errands, followed his urges, tended to his inclinations inner and outer. Carried his many weights. We pursued the girls he loved and those he didn't love with equal fleetness, mechanised the impulses for those pursuits from their source to instrument imperceptibly, we still do and always shall so long as form of body and form of mind continue.

Today is somehow different though. Our work has always been to hold him still, be firm, stay out of the way whilst our counterpart tools - those hands of his - turn the page in time for the last syllable of one page to lead in to the first syllable of the nextthose hands get all the interesting jobs.

We must be still, no shuffle, simply stand whilst he reads, occasionally we take a walk, make a move, straight lines usually, short moves, we're not kept particularly busy, things warm up towards the end of his 'jobs' sometimes, he frees up as we come to the end of the 'rehearsal' bit as he calls it but the demands on us are fairly predictable, we always know what we're going to do next. Readiness is largely unnecessary, you might even say we're free to put our feet up. 
Today's rehearsal was different however, twenty-five years of taking it easy has come to an end here, today. For today we were primed for action, geared up; the old routine duties discarded in favour of new explorations. Today we moved around in his work space just as we move around in his life space. The game was afoot. Fight, flight and everything in between. Suddenly this kind of movement has a place in the work and we have been released from the block. We felt the movements begin all the way from the source and take us, and us in turn taking him in all directions.

In one moment the source fed us a jump like the time he touched the frog that day in the park, when it jumped and so we jumped. Then the shake. That laughter shake. Perhaps it wasn't real work today. Perhaps it was something else. Back to normal tomorrow probably. Let's not get our hopes up. If feet are permitted hopes.

Anyway, must go, we're needed, he's moving for something. The shift to the left, the dip, the twist from the ankle. Must be bed time.

\section{Mind}

So, diary, me again. I've already skipped a few days, but it's the end of our first week and I've got some thoughts. I'm also a bit tipsy having just got home from the pub so don't expect Hemingway tonight. We've spent most of this week improvising in silence; discovering connections to one another on our feet with mind, body and spirit all involved as the director likes to say. I'd been dreading the repetition of improvisations initially, but it turned out there was no repetition; they've all been wildly different. Some of the cast have worked in this way before, but for most of us it's the first time and we all seem to be picking it up fairly quickly. 
I guess I'm still a bit concerned that we haven't spoken any of our lines to each other in heat yet. In a traditional British approach to rehearsals we would have spoken most of the play out to each other by now and got a sense of how the other person is going to interpret the part. Even if we were just sat around the table doing so. None of that with this method though. No reading. I kind of miss it. I'm a bloody good reader you see. Gives me a chance to show what I can do.

We all went to the pub together tonight, Friday night drinks, end of the first week. The evening passed quickly for the most part. The usual habitual actor chat: talk of agents, past jobs and anecdotes. The assistant director Mariko got a few culture shocks I think. Tales of a British actor's life touring in theatrical digs with rapacious landladies are a far cry from studying phenomenology in the comfort of Cambridge. I had a bit of a ding-dong with the director at one point, well not a ding-dong actually, just a debate of sorts. We'd gotten to talking about reading, and he suggested that reading the script whilst trying to act was absurd. He actually used the word absurd. I said that he was basically telling me that I'd been doing it wrong for the past 25 years, but he wriggled out of it by saying it was not wrong, just different. He said it was all a matter of taste. I had to challenge him on that. I mean he was basically saying that his taste is better than the British theatre of the past century. He wriggled out of that as well, something about there not being one taste but many tastes blah blah blah but then did say that these tastes were predominantly driven by script-in-hand rehearsal methods early on in rehearsals. So, reading then, basically. He admitted it, he thinks his way is better so I challenged him on it again and he makes me this proposition: asks me to imagine two productions of the same play happening in parallel universes; same set, same cast, same theatre and I get to 
watch them both on the same night through the clever use of a hypothetical time machine. Everything's the same except one is rehearsed using the script-in-hand process and the other with Active Analysis. He asks me to imagine that on this night, the night I'm going to see it, that the movement of the actors who rehearsed using Active Analysis happens to be almost the exact movement of the parallel production in its script-in-hand universe. Then he asks me whether from what I've experienced of Active Analysis so far do I think if that if I were able to see both of those productions with fresh eyes each time that they would feel somehow different to me. I felt a bit cornered so told him I'd think about it while I was at the bar.

Eyes, lips

Standing there at the bar, in that moment, mind's eye hard at work on the director's proposition he cannot help but be pulled in the direction he knows ends in some form of agreement. Inner senses concur as we, his embodied eyes, catch in our peripheral vision the movement of the barmaid's long blonde hair as her head turns toward our body and the movement of her head leads to the movement of our lips, words released, words pre-planned, scripted one might say, for the drinks order is pre-ordained but only now as her physical life, her blonde hair, her brown eyes, her smile, her hands reaching for the bar and all of her attention focusing on Victor do the words inside find impulse for their release 'Three pints of Guinness, half a lager and a large Pinot please'. And we see our hands settle on the bar, waiting, and we, the eyes, shift to watch her as she reaches down in to the fridge - shift of her hips, arch of back as hands reach and grip the cold glass bottle, beads of condensation dripping from its neck and we see her spine curve and we, the eyes, send the signal of her shape through his, our, body and then his 
body-mind remembers suddenly the Degas drawing of the girl drying herself with a towel after a bath, the curve of her spine, the neck exposed, and then she, barmaid, turns and her eyes connect with his eyes watching, us, and suddenly our face heats in the blush of the captured soul, staring, caught red-handed, then the smile from her lips and our lips too as we, the eyes, avert, and the gold ring around one of our fingers suddenly feels colder. Then we see drinks arrive and the impulse travels to lips as they make the familiar Thank You shape and as they do memory recalls a moment in rehearsal today and he laughs quietly, a laugh to the self. And the mind's eye recalls the improvisation in which silence was broken, when words were first encouraged following their earlier silent improvisations.

\section{Mind}

And I suppose I must confess to you, my Diary friend, that as I was at the bar, having been momentarily distracted by the barmaid, I remembered a moment rehearsing one of the scenes where a piece of cake was passed to one of the actors during the improvisation and they said 'thank you' breaking the silence we had improvised in until then. Such a simple and easily overlooked phrase caused an entire hour's discussion around the nature of the impulse to speak and the blocks to those impulses. The necessity for that tiny phrase had been so deeply embedded in her through the depth of life experience that it came out without any filtering at all. So I gave the director his due and admitted there might be something in this after all. Maybe those two parallel productions he asked me to imagine would be very different in feeling. I still miss the reading though. The rest of the night was much of a muchness, I made up a good light bulb joke about Active Analysis that everyone laughed at then left shortly after. Always leave them wanting more... 


\section{Feet}

And we carried him home, the stagger walk, him sending us the impulse for this way and that way, forward motion just about possible - so disappointing when he does this. All week long he gives us a power we've never had before in his work only to take it away from us with a few hours of real-life liquid consumption. Are all freedoms bought so dear?

\section{Mind}

Second week of rehearsals kicked in for me today, I wasn't called yesterday hence the day off from my diary. Sorry diary, a blank page for you, I expect you enjoyed the silence. Or if you're anything like the actress playing Yelena was today maybe you didn’t. She doesn't seem to have any sense that other people might need a bit of thinking time to themselves. As soon as we walk off the rehearsal floor she’s jabbering away about how it went, comments on this bit, that bit, what do you think the director meant when he said that thing about the bloody thing... aaargggh, she's a nightmare, imagine being married to that! Of course, I bloody well do have to imagine being married to that because I'm meant to love her in the bleeding play! Maybe that's why she does it, maybe she's a haven of peace and tranquility at home, and she's just being a pain in the arse as some sort of exercise. Maybe she trained at that school where they make you get naked and shit in a bucket in front of the rest of your class. Where was that? Can't remember probably an urban myth anyway. Well, other than the jabberwocky chatting incessantly, it wasn't too bad a day. I've been struggling a bit with this big change that Vanya has towards Astrov though. It's the scene in Act four where Astrov is trying to get me to give him the Morphine back that Vanya has stolen. Vanya spends the early part of the scene 
denying it and focusing on anything but and just generally being an evasive, irritating little bastard. He rejects Astrov completely and the next moment he's appealing to him for help, begging even. I've never liked seismic shifts like that to be honest, I just can’t believe in them, I prefer the gradual gentle awakening in a character rather than the penny dropping like a rock. So difficult to let the penny drop when you know it’s going to fall in advance.

\section{Hands, feet, lips, eyes and mind}

And now as he sleeps he is all senses conjoined, without barrier he returns to wholeness, the quiet dark wholeness in which the process of mind shifts easily and rapidly from one vision to another, seismic shifts have no problem here: like the bee which takes flight around the pomegranate conjuring the fish which leaps from the fruit and the tiger which leaps from the fish mouth whilst the long-legged elephant walks across the ocean blue. Victor sleeps.

\section{Mind}

Hello again Diary. First day of week three. Dug out all my books on acting yesterday and arranged them in a way that could help me see the wood from the trees. Had a bit of a cry holding Stanislavski’s book, silly really, don't know where it came from. Just felt like I knew him for a moment, all those years he spent and all these years I've spent - all gone now. We came back to the scene with Astrov today that I'd struggled with last week. My previous concerns seem so insignificant now. I see how I'd been trying to find a logic to this moment that would hold water, but the more I did this the leakier I became. Perhaps I've always been leaky; a dodgy container trying to hold these non-existent 'characters' inside of me senselessly. 
Had a nice chat with Hattie today about the whole process, with opening night fast approaching, we're all getting quite close. She said that the first time she rehearsed in this way the opening performance was a bit of a revelation to her. She used to be very nervous apparently with bursts of proper horrid stage fright making her sick at the thought of going onstage but apparently since working in this way she's a lot more relaxed. I asked whether her fear had been down to remembering the lines, which she felt was partly it and that because Active Analysis begins without lines it took away the feeling that everything rests on them. She said that 'Beginning with nothing and finding words from that made the idea of "nothing happening" more bearable in front of an audience'.

She also thought her previous fear had something to do with the sheer power of the audience 'out there', that they were overwhelming in their presence. She said working in this way had changed her attitude to them, that they were less oppressive now and more of a support and that she could include them in the whole experience of being onstage now without feeling like she was just pretending.

I got a strong sense of this being today for myself as we rehearsed that tricky moment in Act four which I struggled with last week. This time Vanya's words came to me in effortless reaction to being alone with Astrov, just being genuinely attentive to what was there. The whole notion of containing this character within me and being responsible for his shifts and emotions was just absurd. Then on the bus home there were these children playing together, probably only 5 or 6 years old; one of them stared at me for ages smiling and something popped in to my head that Sufi guy wrote about children 
- that they don't come from you but through you. That's how I felt about Vanya today as I spoke those lines to Astrov which last week seemed so impossible:

Just imagine, if one could somehow live the rest of one's life differently. If one could wake up some clear, quiet morning and feel that one had begun life afresh, that the past was all forgotten, had dissolved like smoke. (Weeps) If one could begin a new life [...] Give me some idea how to do it $[\ldots]$ where to begin $[\ldots] .{ }^{\text {iv }}$

\section{References}

Chekhov, A. (1988), Uncle Vanya (trans. M. Frayn), London: Methuen.

Lodge, D. (2002a), Thinks, London: Penguin. (2002b), Consciousness and the Novel, London: Secker and Warburg. McGilchrist, I. (2010), The Master and His Emissary: Totton, Yale University Press. Stanislavski, C. (2008), An Actor’s Work (trans. J. Benedetti), Oxon: Routledge. Wilson, F. R. (1998), The Hand, New York: Vintage.

\section{Notes}

i. The nature of the novel itself and the way novels are uniquely able to illuminate human consciousness have been major factors in the chosen form of this article. David Lodge's title essay in Consciousness and the Novel alongside his own novel Thinks have been significant influences.

ii. The Hand by Frank R. Wilson provides the root for the sections narrated by Victor's body parts. Wilson's premise that 'the hand is as much at the core of human life as the brain itself' (1998: 277) is central to my argument that the freeing of the hands and the rest of the body in the Active Analysis rehearsal method creates an entirely new experience for the actor. 
iii. The Master and his Emissary by Iain McGilchrist is implicitly present throughout this article. The relationship to the 'howness' of things (McGilchrist's phrase) is key here. In choosing the 'howness' of the novel to explore the consciousness of the actor I am attempting to allow the reader to work with their own right-brained howness throughout.

iv. Uncle Vanya by Anton Chekhov in translation by Michael Frayn is the text which Victor is rehearsing and quotes from at the end of the article.

Paul Christie has asserted his right under the Copyright, Designs and Patents Act, 1988, to be identified as the author of this work in the format that was submitted to Intellect Ltd. 